Original Article

\title{
Effects of proprioceptive neuromuscular facilitation stretching and deep-breathing exercises on upper extremity lymphedema in stroke patients
}

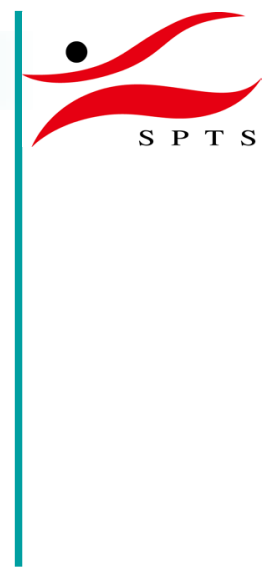

\author{
Woon Taek Hwang, PT, BS ${ }^{1)}$, Yeon-Jae Jeong, PT, PhD²), Seong-Yeol Kim, PT, PhD²), \\ YEON-GYu JEONG, PT, PhD ${ }^{3 *}$ \\ 1) Rehabilitation Medicine, Hanyang University Medical Center, Republic of Korea \\ 2) Department of Physical Therapy, College of Natural Sciences, Kyungnam University, \\ Republic of Korea \\ 3) Department of Physical Therapy, Sangji University: 83 Sangjidae-gil, Wonju-city, Gangwon-do, \\ Republic of Korea
}

\begin{abstract}
Purpose] The purpose of this study was to determine the effects of deep-breathing and proprioceptive neuromuscular facilitation stretching exercises on upper limb lymphedema in stroke patients. [Subjects and Methods] The study consisted of 10 patients with lymphedema that had occurred after stroke. Neurodevelopmental treatment was applied in the same manner as that used for the existing treatment. The subjects performed deep-breathing and stretching exercises three times per week for 4 weeks (12 sessions total). Body water volume in the upper limbs was measured before and after exercise by using an InBody S10 analyzer. [Results] Performance of deep-breathing and stretching exercises significantly reduced body water volume in both the affected and unaffected arms. The extracellular-to-total cellular fluid volume ratio in the affected arm improved to 0.379 after exercise, although this change was not significant. [Conclusion] The results of the present study show that deep-breathing and proprioceptive neuromuscular facilitation stretching exercises reduce upper extremity lymphedema in stroke patients. Key words: Lymphedema, Deep-breathing exercise, Proprioceptive neuromuscular facilitation
\end{abstract}

(This article was submitted Feb. 6, 2016, and was accepted May 7, 2016)

\section{INTRODUCTION}

Affected-side lymphedema (LE) is a frequent aftereffect of stroke ${ }^{1)}$. Although no specific etiology has been identified, immobility, impaired venous return, and paralysis of the sympathetic system are thought to promote LE. LE can increase arm weight, alter appearance, and cause pain and joint contracture ${ }^{1)}$. Because it hinders rehabilitation, LE therapies for stroke patients are needed. Complex decongestive therapy effectively treats edema ${ }^{2}, 3$ ), but involves the onerous daily rewinding of short-stretch bandages because pressure is not maintained. Moreover, the procedures for treating LE in the hands are inconvenient for stroke patients, because their performance requires the aid of a caretaker or therapist ${ }^{1,4)}$. Previous studies have described the effects of deep-breathing and proprioceptive neuromuscular facilitation (PNF) stretching exercises, which can be performed unassisted, on LE. Owing to limited information, it is unclear whether these exercises benefit stroke patients per $\mathrm{se}^{5)}$. Therefore, the aim of present study was to determine the effects of deep breathing and PNF stretching exercises in stroke patients with upper extremity LE.

\footnotetext{
*Corresponding author. Yeon-Jae Jeong (E-mail: jyjion@hanmail.net)

(C)2016 The Society of Physical Therapy Science. Published by IPEC Inc.

This is an open-access article distributed under the terms of the Creative Commons Attribution Non-Commercial No Derivatives (by-nc-nd) License $<$ http://creativecommons.org/licenses/by-nc-nd/4.0/>.
} 


\section{SUBJECTS AND METHODS}

The study consisted of 10 patients with LE that had occurred after stroke. All patients were alert and conscious and could move by themselves. The range of motion of their upper limbs was not limited, and their muscle strength was considered fair.

Neurodevelopmental treatment was applied in the same manner as that used for the existing treatment. The patients performed deep breathing and PNF stretching exercises three times per week for 4 weeks for a total of 12 sessions. Starting in the supine position, they performed shoulder extension, adduction, internal rotation, elbow extension, forearm pronation, and wrist and finger flexion exercises. Then, while inhaling, they slowly performed shoulder flexion, abduction, external rotation, elbow extension, forearm supination, and wrist and finger extension exercises. The arm was kept 8-10 inches away from the ear, and the thumbs were pointed at the floor. When the motions were complete, and maximum stretching of the upper limb muscles was achieved, the patients held their breath for $5 \mathrm{~s}$ while maintaining their positions. They then slowly returned to their starting position while exhaling. This exercise routine was performed 10 times and was followed by a 1-min rest period, and three sets of exercise/rest were performed. The present study conformed to the ethical standards of the Declaration of Helsinki (1975, revised 1983), and the protocol for this study was approved by the institutional review board of Kyungnam University (2014-023-HR-02; IRB). Subjects provided written informed consent prior to testing.

An InBody S10 analyzer (Biospace, Seoul, Korea) was used to measure the body water volume (BWV) in the upper limbs. The patients rested for $30 \mathrm{~min}$ in a supine position before the electrodes were attached to both thumbs and forefingers and just below the ankles of both feet. BWV was measured before and 4 weeks after the exercise intervention began.

The characteristics of the subjects are presented as frequencies or mean $\pm \mathrm{SD}$. Differences in the circumferences at each site of BWV measurement and in the extracellular-to-total cellular (E/F) fluid volume ratios were compared in the paretic and non-paretic limbs by using the Wilcoxon signed-rank test. Statistical analysis was performed by using SPSS version 17.0 software, with the significance level set at $\mathrm{p}<0.05$.

\section{RESULTS}

The general characteristics of the subjects who participated in the study are shown in Table 1. After performance of deep breathing and PNF stretching exercises, the BWVs of the affected and unaffected upper extremities were significantly reduced. Although not significant, the E/T fluid ratios improved to 0.379 in the affected upper extremity, as shown in Table 2.

\section{DISCUSSION}

The present study determined the effects of deep breathing and PNF stretching exercises on upper extremity LE in stroke patients. A previous case report showed that these exercises effectively reduced LE; however, because this report included only one patient, who had not suffered a stroke, this finding cannot be generalized to all patients with LE. The present study was therefore conducted and is most likely the first to show beneficial effects of deep breathing and PNF stretching exercises on BWVs and E/T fluid ratios in stroke patients with upper extremity LE. Its results suggest that these exercises can

Table 1. General characteristics of the subjects $(n=7)$

\begin{tabular}{lc}
\hline Age $($ years $)$, mean $\pm \mathrm{SD}$ & $53.7 \pm 10.8$ \\
Gender $($ male/female), $\mathrm{n}$ & $6 / 4$ \\
Height $(\mathrm{cm})$, mean $\pm \mathrm{SD}$ & $160.0 \pm 8.0$ \\
Weight $(\mathrm{kg})$, mean $\pm \mathrm{SD}$ & $56.7 \pm 5.8$ \\
Hemiplegic side $(\mathrm{right} / \mathrm{left}), \mathrm{n}$ & $4 / 3$ \\
Body mass index $\left(\mathrm{kg} / \mathrm{m}^{2}\right)$, mean $\pm \mathrm{SD}$ & $22.2 \pm 2.1$ \\
Body fat $(\%)$, mean $\pm \mathrm{SD}$ & $15.0 \pm 3.8$ \\
Fat-free mass, mean $\pm \mathrm{SD}$ & $41.8 \pm 4.6$ \\
\hline
\end{tabular}

Table 2. The body water volume (BWV) and extracellular-to-total cellular (E/T) fluid ratio of each upper extremity

\begin{tabular}{lcccccc}
\hline Intervention & $\begin{array}{c}\text { Body } \\
\text { weight }(\mathrm{kg})\end{array}$ & $\begin{array}{c}\text { Body mass } \\
\text { index }\left(\mathrm{kg} / \mathrm{m}^{2}\right)\end{array}$ & $\begin{array}{c}\text { Affected } \\
\text { BWV }(\mathrm{ml})\end{array}$ & $\begin{array}{c}\text { Unaffected } \\
\text { BWV }(\mathrm{ml})\end{array}$ & $\begin{array}{c}\text { Affected E/T } \\
\text { fluid ratio (\%) }\end{array}$ & $\begin{array}{c}\text { Unaffected E/T } \\
\text { fluid ratio (\%) }\end{array}$ \\
\hline Before & $56.7 \pm 5.8$ & $22.2 \pm 2.1$ & $1.58 \pm 0.23$ & $1.46 \pm 0.25$ & $0.38 \pm 0.01$ & $0.38 \pm 0.01$ \\
After & $56.4 \pm 4.3$ & $22.2 \pm 2.0$ & $1.46 \pm 0.26^{*}$ & $1.39 \pm 0.27^{*}$ & $0.38 \pm 0.01$ & $0.38 \pm 0.01$ \\
\hline$* \mathrm{p}<0.05$ & & & & &
\end{tabular}


effectively alleviate LE in such patients, and thus are useful interventions.

Following deep breathing and PNF stretching exercises, the BWVs in the affected and unaffected upper limbs decreased to $1.457 \pm 0.3 \mathrm{ml}$ and $1.391 \pm 0.3 \mathrm{ml}$, respectively, and the ratio of the extracellular fluid volume to the total volume of water in the affected upper limb decreased (albeit insignificantly) to $0.002 \%$. These results indicate that deep breathing and PNF stretching exercises can alleviate LE in stroke patients. A recent study showed that these exercises effectively reduced edema, although the subjects in that study differed from those in the present study ${ }^{5}$. In another study, deep breathing and PNF stretching exercises reduced the circumference of the following: the armpit (by $0.5 \mathrm{~cm}$ ), the arm $10 \mathrm{~cm}$ above and below the elbow (both by $1 \mathrm{~cm}$ ), the elbow (by $0.5 \mathrm{~cm}$ ), and the back of the hand (by $0.5 \mathrm{~cm})^{6}$. They also eliminated $100 \mathrm{ml}(9.4 \%)$ of the BWV in the right upper extremity and decreased the E/T fluid ratio by $0.005 \%{ }^{6}$. Moreover, upper extremity edema decreased by $46 \mathrm{ml}(5.8 \%), 50 \mathrm{ml}(5.3 \%), 46 \mathrm{ml}(4.3 \%)$, and $33 \mathrm{ml}(3.5 \%)$ immediately, 30 minutes, 24 hours, and 1 week after completion of gentle arm and deep-breathing exercises ${ }^{6)}$. When re-measured after exercising for 1 month, the edema had decreased by $101 \mathrm{ml}(9.0 \%)^{6}$, which was similar to the results in the present study.

Although the effects of PNF on edema are underreported, a previous study found that PNF stretching of upper arms with LE reduced the rate of edema by $27.21 \%$ (from $63.49 \%$ to $36.28 \%)^{7}$ ). According to Hindle et al. ${ }^{8}$ ) , the decline in muscle energy consumption during PNF exercise apparently accounts for the subsequent reduction in LE. Overall, as shown in the present study and previous studies, deep breathing and upper extremity exercises appear to be beneficial for stroke patients with upper extremity LE.

The present study has three limitations. First, it was a pilot study without a control group. Therefore, its findings may not apply to all stoke patients with upper extremity LE. Second, the correlation between exercise performance and edema was imprecise. Third, the rehabilitation period was only 4 weeks, and similar studies with longer intervention times are required for more conclusive results. However, the present study is meaningful because it suggests that a simple, cost-free exercise routine can reduce upper extremity LE in stroke patients in the absence of other treatments. Lastly, it provides objective data on a relatively unexplored topic. Owing to the limitations of the present study, further studies are needed.

\section{REFERENCES}

1) Gustafsson L, Walter A, Bower K, et al.: Single-case design evaluation of compression therapy for edema of the stroke-affected hand. Am J Occup Ther, 2014, 68: 203-211. [Medline] [CrossRef]

2) Mayrovitz HN: The standard of care for lymphedema: current concepts and physiological considerations. Lymphat Res Biol, 2009, 7: 101-108. [Medline] [CrossRef]

3) Szuba A, Cooke JP, Yousuf S, et al.: Decongestive lymphatic therapy for patients with cancer-related or primary lymphedema. Am J Med, 2000, 109: 296-300. [Medline] [CrossRef]

4) Yang EJ, Kim HJ, Ahn HS, et al.: The effect of early upper extremities passive exercise on the hand edema and upper spasticity of the hemiplegia patient after stroke. J Korean Clin Nurse Res, 2006, 12: 147-157.

5) Hwang WT, Chung SH, Chung MS, et al.: Effect of proprioceptive neuromuscular facilitation D2 flexion and breathing exercises on lymphedema without a short stretch compression bandage. J Phys Ther Sci, 2015, 27: 3341-3343. [Medline] [CrossRef]

6) Moseley AL, Piller NB, Carati CJ: The effect of gentle arm exercise and deep breathing on secondary arm lymphedema. Lymphology, 2005, 38: 136-145. [Medline]

7) Hwang O, Ha K, Choi S: The effects of PNF techniques on lymphoma in the upper limbs. J Phys Ther Sci, 2013, 25: 839-841. [Medline] [CrossRef]

8) Hindle KB, Whitcomb TJ, Briggs WO, et al.: Proprioceptive neuromuscular facilitation (PNF): its mechanisms and effects on range of motion and muscular function. J Hum Kinet, 2012, 31: 105-113. [Medline] [CrossRef] 